\title{
Symptoms and Well-Being in Older Hospitalized Patients with Cognitive Impairment, As Self-Reported and Reported in Patient Records: A Quantitative Exploratory Subgroup Analysis
}

\author{
Yvonne A. Johansson ${ }^{a, c}$ Catharina Gillsjö ${ }^{b, d}$ Elisabeth Kenne Sarenmalm ${ }^{a, b}$, e \\ a Skaraborg Hospital, Skövde, Sweden; ${ }^{b}$ University of Skövde, Skövde, Sweden; ‘ Jönköping University, The \\ Research School of Health and Welfare, Aging Research Network-Jönköping (ARN-J), Jönköping, Sweden; ${ }^{d}$ College \\ of Nursing, University of Rhode Island, Kingston, RI, USA; ${ }^{e}$ Centre for Person-Centred Care (GPCC), Sahlgrenska \\ Academy, University of Gothenburg, Gothenburg, Sweden
}

\section{Keywords}

Cognitive impairment · Delirium · Older hospitalized patients · Self-reported symptoms · Well-being · Risk factors . Poor outcomes

\begin{abstract}
Introduction: Given the aging population and the high prevalence of cognitive impairment in older hospitalized patients, it is essential to provide good fundamental care to these vulnerable patients, who easily might be affected by poor outcomes as delirium. Risk factors for delirium are, for example, cognitive impairment, old age, pain, and sleep deprivation. Different symptoms are often unidentified in hospitals, and associated with poor well-being, but this is rarely studied in older patients with cognitive impairment. The study aim was to examine symptoms and sense of well-being in older hospitalized patients with cognitive impairment, as self-reported and reported in patient records. Methods: Exploratory quantitative subgroup $(n=25)$ analysis of a point-prevalence study $(n=210)$. Inclusion criteria were age $\geq 65$, and cognitive impairment. Data were collected through structured interviews, validated instruments, and patient records. Associations between well-being and symptoms, and
\end{abstract}

concordance between the occurrence of self-reported symptoms and symptoms reported in patient records were analyzed. Results: The patients reported severe and distressing symptoms that were sparsely reported (14\%) in their records. As well were cognitive impairment, and the patients' own descriptions of their well-being. Some symptoms and the total symptom burden were associated with poor wellbeing. Discussion/Conclusion: To our knowledge, this hypothesis-generating study is one of few studies that describe both symptoms and well-being as self-reported and reported in patient records, in vulnerable patients due to old age, cognitive impairment, and hospitalization. Despite the limited sample size, the results indicate that symptoms were more insufficient alleviated in these patients compared to patients with normal cognitive function in other studies. To our knowledge, this has not been shown previously. Additionally, patients' own experiences were sparsely reported in their records. A larger sample size and longitudinal design has the potential to determine if symptom alleviation differs between patients with and without cognitive impairment, and if a total symptom burden increases the risk of poor outcomes as delirium in vulnerable patients.

(c) 2021 The Author(s)

Published by S. Karger AG, Basel karger@karger.com www.karger.com/dee

Karger $\stackrel{\text { ' }}{5}$

GOPEN ACCESS
(C) 2021 The Author(s)

Published by S. Karger AG, Basel

This is an Open Access article licensed under the Creative Commons Attribution-NonCommercial-4.0 International License (CC BY-NC) (http://www.karger.com/Services/OpenAccessLicense), applicable to the online version of the article only. Usage and distribution for commercial purposes requires written permission.
Correspondence to:

Yvonne A Johansson, yvonne.a.johansson@vgregion.se 


\section{Introduction}

Preventing poor outcomes for hospitalized patients is utterly important, especially for vulnerable patients such as older patients with cognitive impairment who might be easily affected by poor outcomes such as delirium [1, $2]$. The causes of cognitive impairment vary, but in this study the term is used regardless of the underlying cause, in line with Torisson et al. [3]. Cognitive impairment is associated with old age and is a common co-morbidity in older hospitalized patients $[1,3,4]$ with a prevalence of more than $40 \%[3,4]$. However, cognitive impairment is poorly understood and managed in hospitals $[2,5-7]$ and often undetected and underdiagnosed $[3,7,8]$. Additionally, cognitive impairment and old age are the 2 most important risk factors for delirium [1]. Other risk factors are, for example, acute illness, hospitalization, sleep deprivation [9], and pain [5, 10-12]. Preventing delirium in hospitals is important [1] as this condition is associated with several adverse outcomes [7, 13], including death [7]. About $40 \%$ of all cases of delirium can be prevented by providing good fundamental care $[2,14]$, for example, symptom alleviation of sleeping difficulties $[5,10]$, and pain [5]. The most vulnerable patients, such as patients with many predisposing factors, may develop delirium as a result of just a small precipitating factor. Therefore, it is essential to minimize modifiable risk factors that can trigger delirium [9].

Regardless of diagnosis, hospitalized patients often have multiple co-occurring symptoms, yet they do not always receive sufficient symptom alleviation $[15,16]$. Symptoms may even remain undetected and untreated $[17,18]$ with negative effects on the patient's well-being [19]. The cornerstone of symptom management is routine symptom assessment [20], preferably with validated symptom assessment tools $[16,17]$. Important aspects of a symptom are severity/intensity reflecting the degree of discomfort, and distress reflecting the degree of suffering [21].

Well-being and different symptoms, above all depression and pain, have been studied in patients with cognitive impairment in different settings [22, 23]. However, this is rarely studied in hospitals $[12,17,18]$. Professionals have reported the risk of overlooking the needs of patients who have difficulties communicating, for example, patients with cognitive impairment [14]. Nevertheless, older hospitalized patients with cognitive impairment may experience difficulties to spontaneously inform professionals about their symptoms or well-being. Therefore, it can be assumed that these patients have undetected symptoms that might both affect their well-being and increase the risk of other poor outcomes. The aim of this study was to examine symptoms and sense of well-being in older hospitalized patients with cognitive impairment, as self-reported and reported in patient records.

\section{Material and Methods}

\section{Design and Setting}

Exploratory quantitative subgroup analysis of a larger point prevalence study (main study) $[16,24]$ assessing symptoms and well-being in patients in somatic wards in a county hospital in Sweden.

\section{Sample}

In the main study, inpatients aged $\geq 18$ in somatic wards were included during a single day. In total, 531 patients were eligible for participation. Registered nurses excluded patients according to the exclusion criteria $(n=108)$ : not available for assessment, inability to communicate, terminally ill, or other reasons that made participation impossible. After receiving oral and written information about the study, 208 patients declined participation, and 5 did not complete the assessments. In total, 210 patients consented in writing to participate in the main study. In the present subgroup analysis, the inclusion criteria were age $\geq 65$, and cognitive impairment according to the screening test Short Portable Mental Status Questionnaire (SPMSQ) [25]. It was estimated that $42-52$ of the 210 patients fulfilled these inclusion criteria since $50 \%$ of all inpatients are aged $\geq 65$ [26], and the prevalence of cognitive impairment is $40 \%$ in that age $[3,4]$, or that approximately $25 \%$ of all inpatients have cognitive impairment [2]. However, cognitive impairment was present in just 25 (12\%) patients. Therefore, the current study is a hypothesis-generating study, as the results can provide valuable information for further studies.

\section{Data Collection}

Data were collected through structured patient interviews with predetermined response options, and from patient records. Thirdyear bachelor nursing students had been trained to collect data through the instruments used in the main study. On the day of data collection, the research team was present at the hospital to provide support to the students. The study procedure is described in detail elsewhere [24].

\section{Patient Measurements}

Cognitive function was measured with the SPMSQ, a brief 10 -question screening test for short-term and long-term memory, orientation, and mathematical skills $[25,27]$. The test has good validity, reliability, and feasibility [28]. In Sweden, the number of correct answers $(0-10)$ is commonly used. A score $\leq 7$ implies cognitive impairment [29].

Activities of daily living (ADL) was measured with the Barthel ADL Index, where 10 activities are asked for: feeding, bathing, grooming, dressing, bowel continence, bladder continence, toilet use, transfers, mobility, and stairs. Each activity is scored from 0 to 15 , where 0 indicates dependent and the highest score independent. The total score is calculated, and a score of 100 indicates that the patient is totally functionally independent [30]. 
Table 1. Demographic and clinical characteristics of participants $(n=25)$

\begin{tabular}{lccl}
\hline Demographic and clinical data & $\begin{array}{l}\text { Women } \\
(n=14)\end{array}$ & $\begin{array}{l}\text { Men } \\
(n=11)\end{array}$ & $\begin{array}{l}\text { Total } \\
(n=25)\end{array}$ \\
\hline Age, median (Q1-Q3) & $83.5(79.8-90)$ & $81(76-89)$ & $81(78-89.5)$ \\
Acute admission, $n(\%)$ & $13(93)$ & $9(82)$ & $22(88)$ \\
Length of stay, median (Q1-Q3) & $10.5(7-15.8)$ & $10(5-18)$ & $10(7-16.5)$ \\
ADL, median (Q1-Q3) & $75(45-96.3)$ & $90(75-95)$ & $85(57.5-95)$ \\
\hline
\end{tabular}

The patients were asked to describe their experience of 8 common symptoms and their sense of well-being the past day. The questions about symptoms were divided into 3 parts and designed in accordance with 3 widely used and validated assessment instruments. The symptoms asked for were drawn from the Edmonton Symptom Assessment Scale (ESAS) [20, 31]: pain, dyspnea, fatigue, sleeping difficulties, nausea, appetite, depression, anxiety, and overall well-being [20]. The questions regarding symptom occurrence were answered with yes or no, as in the European Organization for Research and Treatment of Cancer Quality of Life Questionnaire in Cancer (EORTC QLQ-C30) [32], except for appetite, for example, "Have you had pain?". If the patient answered yes, symptom severity and distress were asked for, as in the Memorial Symptom Assessment Scale (MSAS) [33] "How severe was it?" and "How much did it bother you?". When rating symptom severity and distress, appetite, and well-being, an 11-point (0-10) Numerical Rating Scale (NRS) was used. Severity and distress ranged from $0=$ No severity/distress, to $10=$ Worst possible. The questions about appetite and well-being were expressed as "How has your appetite been?" ( $0=$ Very good, to $10=$ Very poor $)$, and "How do you perceive your well-being?" $(0=$ Worst possible, to $10=$ Best possible).

\section{Patient Record Reviews}

A review of all the documentation carried out by healthcare professionals in patient records was conducted by 2 of the authors (Y.A.J. and E.K.S.) together, using a review protocol. The review included age, gender, acute/elective admission, length of hospital stay, main diagnosis, cognitive function, symptoms during 1 day before and 2 days after the assessments, and patients' sense of wellbeing for the entire care episode.

\section{Analysis}

Descriptive statistics were calculated for all data. Spearman's correlation coefficient was used to determine associations between well-being and the severity and distress of the symptoms asked for, and the total symptom burden (score) of, respectively, severity and distress. A $p$ value of 0.05 (2-tailed) was considered statistically significant. The concordance (\%) between the occurrence of selfreported symptoms and symptoms reported in patient records was analyzed. All statistical analyses were carried out using SPSS Statistics software, version 22.0 for Windows (IBM Corp, Armonk, NY, USA).

\section{Results}

\section{Demographic and Clinical Data}

The SPMSQ [29] indicated that $17(68 \%)$ of the 25 patients had mild cognitive impairment, 7 moderate, and 1 severe cognitive impairment. Cognitive impairment was reported in 15/25 (60\%) patient records. The most frequent main diagnoses were cardiovascular diseases including stroke $(n=11)$, pulmonary diseases $(n=3)$, and gastrointestinal diseases $(n=3)$. Demographic and clinical data are presented in Table 1.

\section{Symptoms and Well-Being}

Twenty-two (88\%) patients reported between 1 and 6 (median 4) symptoms each, women 4 and men 2 . The patients' appetite was relatively good, with a median value of 2.0 on the 11 -point NRS $(0=$ Very good, to $10=$ Very poor). Of the patients' self-reported symptoms, $14 \%$ were reported in their records. The self-reported symptoms of pain, nausea, and dyspnea were reported to a higher degree (18\%) than anxiety and depression (4.5\%). There was no score of severity or distress reported in the records. In Table 2, the occurrence, severity and distress of the selfreported symptoms are presented, together with the concordance (\%) between the occurrence of self-reported symptoms and symptoms reported in patient records.

The median for the patients' self-reported well-being, as described in the ESAS $(0=$ Worst possible, to $10=$ Best possible) was 5.0, with 5.0 for women and 6.0 for men. Moderate negative associations were found between poorer well-being and sleeping difficulty severity $(-0.53$, $p=0.01)$, sleeping difficulty distress $(-0.48, p=0.02)$, poor appetite $(-0.42, p=0.04)$, and the total distress symptom score $(-0.41, p=0.04)$. Well-being was described in 10 (40\%) patient records. In 2 of these, the descriptions reflected the patient's own experiences, for example, "Experiencing that he needs to have his oxygen 'otherwise things will not go well,' according to the patient." In 8 records, the healthcare professionals described how 
Table 2. Occurrence, severity, and distress of self-reported symptoms, and symptoms reported in patient records (\% of self-reported; $n=25$ )

\begin{tabular}{llccc}
\hline Symptom & $\begin{array}{l}\text { Occurrence, } \\
\left(\%^{*}\right)\end{array}$ & $\begin{array}{l}\text { Severity, median } \\
(\text { mean })\end{array}$ & $\begin{array}{l}\text { Distress, median } \\
(\text { mean })\end{array}$ & $\begin{array}{l}\text { In patient records, } \\
n\left(\%^{* *}\right)\end{array}$ \\
\hline Fatigue & $19(76)$ & $5(6)$ & $5(5.9)$ & $5(20)$ \\
Pain & $12(48)$ & $6.5(6.6)$ & $6.5(6.6)$ & $1(4)$ \\
Depression & $11(44)$ & $6(6.3)$ & $5(4.8)$ & $0(0)$ \\
Dyspnea & $11(44)$ & $5(6.6)$ & $7(6)$ & $2(8)$ \\
Anxiety & $11(44)$ & $6.5(6.1)$ & $5(5.7)$ & $1(4)$ \\
Sleeping difficulties & $10(40)$ & $7(6.8)$ & $7.5(7.2)$ & $0(0)$ \\
Nausea & $5(20)$ & $5(4.9)$ & $6(6.2)$ & $2(8)$ \\
Total number of symptoms & $\mathbf{7 9}$ & - & - & $\mathbf{1 1}(\mathbf{1 4})$ \\
\hline \multicolumn{4}{c}{$\%$ of the patients $(n=25)}$. & $* * \%$ of the self-reported symptoms. \\
\hline
\end{tabular}

they perceived the patient's well-being using the terms "the patient appears to/seems to" feel well, tired, exhausted, or dejected and sad. One example is "Seems to be in relatively good shape."

\section{Discussion/Conclusion}

This is one of few studies that describe both symptoms and well-being as self-reported and reported in patient records, in vulnerable patients due to old age, cognitive impairment, and hospitalization. To prevent poor outcomes, it is utterly important to provide good fundamental and patient safe care $[1,2]$. However, according to study results, this was done inconsistently. Although all patients included in the study had cognitive impairment according to the SPMSQ, cognitive impairment was just reported in $60 \%$ of the patient records. This suggests that cognitive impairment was not identified and reported, which is similar to other studies $[3,7,8]$. To provide good and patient safe care, a more active approach to identify patients with cognitive impairment is required $[2,3]$. Of the patients' self-reported symptoms, just $14 \%$ were reported in their records, which indicates that most of the patients had unmet needs regarding symptom alleviation, and that their self-reported symptoms were undetected and untreated. In previous research, the concordance between self-reported symptoms and symptoms reported in patient records has been about 50\%. Compared to this study, those patients were younger, and they had normal cognitive function $[17,18]$. Several symptoms were reported as severe and distressing, especially pain and sleeping difficulties, symptoms that have been shown to trigger delirium [5,9-12]. Even if symptom severity and distress are important aspects [21], this was not reported at all in the patient records. Possibly it had not been evaluated. For several of the symptoms, treatment should have been considered as the symptom scores were $\geq 4$ on the NRS [16]. Symptom alleviation may have been provided temporarily and reported in the records' medication module but there was no evaluation of the effects of such medication. Some of the self-reported symptoms, and the total symptom burden were associated with poor sense of wellbeing, in line with studies of patients with normal cognitive function [19].

Not only cognitive impairment and symptoms were sparsely reported in the patient records. The same pattern was found regarding the patients' sense of well-being, and their own perspective of well-being. As both well-being and symptoms always refer to the person's subjective experience, it is essential to listen carefully to the patient's narrative and experiences [19], and not assume their experiences. Median length of hospital stay was 10 days, which implies that for many patients there might have been time to address the patients' experiences. As these patients often have difficulties taking initiatives and expressing themselves [34], healthcare professionals must take responsibility for initiating dialogues, and regularly and systematically ask about the patients' symptoms and well-being. As recommended, use of validated assessment tools could be helpful in this process $[16,17,20]$. One way to promote the patient's inside perspective, is the use of the holistic person-centered care approach, since it emanates from each patient's subjective experiences, abilities, and individual needs [35]. The patients in this study were older, and a lack of interest in geriatric 
care issues in hospitals and ageist attitudes, with the expectation that cognitive impairment [36] and symptoms, for example, pain are natural and inevitable in the aging process, may have contributed to the results [37]. Additionally, professionals might have perceived that it was not important to report patients' experiences in their records, although the records are a vital source of information about the patient and the patients' care, and one essential way to ensure good quality of care and patient safety [38-40].

Given the aging population and the high prevalence of cognitive impairment in hospitals, study results support previous studies that have stated that changes to care processes are required $[2,3,14,41]$ and fundamental care is suggested [2]. To pay attention to and increase the knowledge about cognitive impairment in hospitals is important $[3,42]$. Additionally, to include patients with cognitive impairment in research is essential $[1,2,43,44]$. Studies have shown that these patients can participate in research [45], which this study acknowledges. However, for patients with severe cognitive impairment, other methods may be needed.

A limitation to this study was mainly the small sample size, and the low response rate in the main study. The limited sample size might be caused by the fact that patients with severe cognitive impairment probably were excluded in the main study. Another limitation is that the selfreported symptoms were restricted to the symptoms in the ESAS, and the patients might have had other severe and distressing symptoms that were not asked for. However, the symptoms in ESAS are common in patients with different diagnosis [20]. The strength of the study was that the interviewers were trained to carry out the structured interviews with reliable and validated instruments, and to be responsive to the patients and interrupt the interviews if the patients showed discomfort or tiredness. As the patient record review was dependent on adequate and complete reporting in the records, the review included more days besides the study day.

\section{Conclusions and Future Research}

Despite the limited sample size, the results in this hypothesis-generating study provided an insight into symptom alleviation of vulnerable patients due to old age, cognitive impairment, and hospitalization. Results indicate that several symptoms were more insufficiently alleviated in these patients compared to patients with normal cognitive function in other studies $[17,18]$. To our knowledge, this has not been shown previously. Additionally, patients' own experiences were sparsely reported in their records. A larger sample size and longitudinal design has the potential to determine if symptom alleviation differs between patients with and without cognitive impairment, and if poor symptom alleviation and a high symptoms burden increase the risk of poor outcomes such as delirium and readmission in these vulnerable patients.

\section{Acknowledgement}

We would like to thank Professor Öhlén and his research group $\left(\mathrm{iPC}^{2}\right)$ at the Institute of Health and Care Sciences, Gothenburg University, Gothenburg, Sweden, for permission to use the data.

\section{Statement of Ethics}

Ethical approval was obtained from the Regional Ethical Review Board in Gothenburg (Reg. No. 604-10). The Declaration of Helsinki ethical principles were followed [46]. All participants gave their written informed consent for inclusion in this study before participating.

\section{Conflict of Interest Statement}

The authors declare no conflict of interest.

\section{Funding Sources}

The main study was supported by the Health and Medical Care Committee of the Regional Executive Board, Västra Götaland Region, Sweden; the Sahlgrenska University Hospital Foundations, Gothenburg, Sweden; and the Ulla-Carin Lindquist Foundation, Sweden. The current study was funded by the Research and Development Center Skaraborg Hospital, Sweden.

\section{Author Contributions}

Study design: Researchers (including E.K.S.) in the research group "Investigating Person-Centered Palliative Care, iPC 2"; Coordination and information in the study site: Y.A.J.; Data collection: Nursing students (structured interviews): Y.A.J., E.K.S. (patient records); Statistical analysis and interpretation: Y.A.J., C.G., E.K.S.; Drafting of manuscript: Y.A.J., C.G., E.K.S. All authors read and approved the final manuscript. 


\section{References}

1 Jackson TA, Gladman JR, Harwood RH, MacLullich AM, Sampson EL, Sheehan B, et al. Challenges and opportunities in understanding dementia and delirium in the acute hospital. PLoS Med. 2017 Mar;14(3):e1002247.

2 Fogg C, Griffiths P, Meredith P, Bridges J. Hospital outcomes of older people with cognitive impairment: an integrative review. Int $J$ Geriatr Psychiatry. 2018 Jun;33(9):1177-97.

3 Torisson G, Minthon L, Stavenow L, Londos E. Cognitive impairment is undetected in medical inpatients: a study of mortality and recognition amongst healthcare professionals. BMC Geriatr. 2012 Aug;12(1):47.

4 Sampson EL, Blanchard MR, Jones L, Tookman A, King M. Dementia in the acute hospital: prospective cohort study of prevalence and mortality. Br J Psychiatry. 2009 Jul;195(1):61-6.

5 Inouye SK, Westendorp RG, Saczynski JS. Delirium in elderly people. Lancet. 2014 Mar;383(9920):911-22.

6 Johansson YA, Bergh I, Ericsson I, Sarenmalm EK. Delirium in older hospitalized patients-signs and actions: a retrospective patient record review. BMC Geriatr. 2018 Feb;18(1):43

7 Welch C, McCluskey L, Wilson D, Chapman GE, Jackson TA, Treml J, et al. Delirium is prevalent in older hospital inpatients and associated with adverse outcomes: results of a prospective multi-centre study on World Delirium Awareness Day. BMC Med. 2019 Dec;17(1):229.

8 Ritter SRF, Cardoso AF, Lins MMP, Zoccoli TLV, Freitas MPD, Camargos EF. Underdiagnosis of delirium in the elderly in acute care hospital settings: lessons not learned. Psychogeriatrics. 2018 Jul;18(4):268-75.

9 Inouye SK. Delirium-A Framework to Improve Acute Care for Older Persons. J Am Geriatr Soc. 2018 Mar;66(3):446-51.

10 Fong TG, Tulebaev SR, Inouye SK. Delirium in elderly adults: diagnosis, prevention and treatment. Nat Rev Neurol. 2009 Apr;5(4):210-20.

11 Mehta SS, Siegler EL, Henderson CR Jr, Reid MC. Acute pain management in hospitalized patients with cognitive impairment: a study of provider practices and treatment outcomes. Pain Med. 2010 Oct;11(10):1516-24.

12 Feast AR, White N, Lord K, Kupeli N, Vickerstaff V, Sampson EL. Pain and delirium in people with dementia in the acute general hospital setting. Age Ageing. 2018 Nov;47(6):841-6.

13 Fong TG, Vasunilashorn SM, Libermann T, Marcantonio ER, Inouye SK. Delirium and Alzheimer disease: A proposed model for shared pathophysiology. Int J Geriatr Psychiatry. 2019 Jun;34(6):781-9.
14 Ernst J, Petry H, Luethi N, Naef R. Acute care delivery to persons with cognitive impairment: a mixed method study of health professionals' care provision and associated challenges. Aging Ment Health. 2020 Oct;24(10):1726-35.

15 Kris AE, Dodd MJ. Symptom experience of adult hospitalized medical-surgical patients. J Pain Symptom Manage. 2004 Nov;28(5):451-

16 Henoch I, Sawatzky R, Falk H, Fridh I, Jakobsson Ung E, Sarenmalm EK, et al. Symptom distress profiles in hospitalized patients in Sweden: a cross-sectional study. Res Nurs Health. 2014 Dec;37(6):512-23.

17 Florin J, Ehrenberg A, Ehnfors M. Patients' and nurses' perceptions of nursing problems in an acute care setting. J Adv Nurs. 2005 Jul;51(2):140-9.

18 Sikorskii A, Wyatt G, Tamkus D, Victorson $\mathrm{D}$, Rahbar MH, Ahn S. Concordance between patient reports of cancer-related symptoms and medical records documentation. J Pain Symptom Manage. 2012 Sep;44(3):362-72.

19 Wallström S, Ekman I. Person-centred care in clinical assessment. Eur J Cardiovasc Nurs. 2018 Oct;17(7):576-9.

20 Hui D, Bruera E. The Edmonton Symptom Assessment System 25 Years Later: Past, Present, and Future Developments. J Pain Symptom Manage. 2017 Mar;53(3):630-43.

21 Rhodes VA, Watson PM. Symptom distressthe concept: past and present. Semin Oncol Nurs. 1987 Nov;3(4):242-7.

22 Ericsson I. Välbefinnande och demens Aspekter på välbefinnande hos äldre personer med måttlig till svår demenssjukdom. (Diss.). Dissertation series no. 19. Jönköping: Hälsohögskolan, Högskolan i Jönköping 2011.

23 Björk S, Juthberg C, Lindkvist M, Wimo A, Sandman PO, Winblad B, et al. Exploring the prevalence and variance of cognitive impairment, pain, neuropsychiatric symptoms and ADL dependency among persons living in nursing homes; a cross-sectional study. BMC Geriatr. 2016 Aug;16(1):154.

24 Henoch I, Jakobsson Ung E, Ozanne A, Falk H, Falk K, Kenne Sarenmalm E, et al. Nursing students' experiences of involvement in clinical research: an exploratory study. Nurse Educ Pract. 2014 Mar;14(2):188-94.

25 Pfeiffer E. A short portable mental status questionnaire for the assessment of organic brain deficit in elderly patients. J Am Geriatr Soc. 1975 Oct;23(10):433-41.

26 Socialstyrelsen. Vård och omsorg om äldre. Lägesrapport 2020.

27 Tullai-McGuinness S, Madigan EA, Fortinsky RH. Validity testing the Outcomes and Assessment Information Set (OASIS). Home Health Care Serv Q. 2009;28(1):45-57.

28 Smith MJ, Breitbart WS, Platt MM. A critique of instruments and methods to detect, diagnose, and rate delirium. I Pain Symptom Manage. 1995 Jan;10(1):35-77.
29 Al-Ani AN, Flodin L, Söderqvist A, Ackermann $\mathrm{P}$, Samnegård E, Dalén $\mathrm{N}$, et al. Does rehabilitation matter in patients with femoral neck fracture and cognitive impairment? A prospective study of 246 patients. Arch Phys Med Rehabil. 2010 Jan;91(1):51-7.

30 Mahoney FI, Barthel DW. FUNCTIONAL EVALUATION: THE BARTHEL INDEX. Md State Med J. 1965 Feb;14:61-5.

31 Bruera E, Kuehn N, Miller MJ, Selmser P, Macmillan K. The Edmonton Symptom Assessment System (ESAS): a simple method for the assessment of palliative care patients. J Palliat Care. 1991;7(2):6-9.

32 Aaronson NK, Ahmedzai S, Bergman B, Bullinger M, Cull A, Duez NJ, et al. The European Organization for Research and Treatment of Cancer QLQ-C30: a quality-of-life instrument for use in international clinical trials in oncology. J Natl Cancer Inst. 1993 Mar;85(5):365-76.

33 Browall M, Kenne Sarenmalm E, Nasic S, Wengström Y, Gaston-Johansson F. Validity and reliability of the Swedish version of the Memorial Symptom Assessment Scale (MSAS): an instrument for the evaluation of symptom prevalence, characteristics, and distress. J Pain Symptom Manage. 2013 Jul;46(1):131-41.

34 American Psychiatric Association. Diagnostic and Statistical Manual of Mental Disorders (DSM-5). Washington (DC): American Psychiatric Association; 2013.

35 Health Foundation. Person-centred care made simple. What everyone should know about person-centred care. 2014.

36 Teodorczuk A, Reynish E, Milisen K. Improving recognition of delirium in clinical practice: a call for action. BMC Geriatr. 2012 Sep;12(1):55.

37 Gillsjö C, Schwartz-Barcott D, Bergh I. Learning to Endure Long-Term Musculoskeletal Pain in Daily Life at Home: A Qualitative Interview Study of the Older Adult's Experience. J Gerontol Geriatr Res. 2013;10/21(2):1000136.

38 Pakhomov SV, Jacobsen SJ, Chute CG, Roger VL. Agreement between patient-reported symptoms and their documentation in the medical record. Am J Manag Care. 2008 Aug;14(8):530-9.

39 Echaiz JF, Cass C, Henderson JP, Babcock HM, Marschall J. Low correlation between self-report and medical record documentation of urinary tract infection symptoms. Am J Infect Control. 2015 Sep;43(9):983-6.

40 Høgsnes L, Danielson E, Norbergh KG, Melin-Johansson C. Healthcare professionals' documentation in nursing homes when caring for patients with dementia in end of life - a retrospective records review. J Clin Nurs. 2016 Jun;25(11-12):1663-73. 
41 Moyle W, Borbasi S, Wallis M, Olorenshaw R, Gracia N. Acute care management of older people with dementia: a qualitative perspective. J Clin Nurs. 2011 Feb;20(3-4):420-8.

42 Digby R, Lee S, Williams A. The experience of people with dementia and nurses in hospital: an integrative review. J Clin Nurs. 2017 May;26(9-10):1152-71.
43 Moore TF, Hollett J. Giving voice to persons living with dementia: the researcher's opportunities and challenges. Nurs Sci Q. 2003 Apr;16(2):163-7.

44 Beuscher L, Grando VT. Challenges in conducting qualitative research with individuals with dementia. Res Gerontol Nurs. 2009 Jan;2(1):6-11.
45 Moyle W, Murfield JE, Griffiths SG, Venturato L. Assessing quality of life of older people with dementia: a comparison of quantitative self-report and proxy accounts. J Adv Nurs. 2012 Oct;68(10):2237-46.

46 World Medical Association. World Medical Association Declaration of Helsinki: ethical principles for medical research involving human subjects. JAMA.2013 Nov;310(20):2191- 